Max-Planck-Institut für demografische Forschung

Max Planck Institute for Demographic Research

Doberaner Strasse 114 - D-18057 Rostock - GERMANY

Tel +49 (0) 3812081 - 0; Fax +49 (0) 3812081 - 202;

http://www.demogr.mpg.de

MPIDR WORKING PAPER WP 2002-045

SEPTEMBER 2002

\title{
Age-structured optimal control in population economics
}

Gustav Feichtinger (or@e119ws1.tuwien.ac.at) Alexia Prskawetz (fuernkranz@ demogr.mpg.de) Vladimir M. Veliov (vveliov@eos.tuwien.ac.at)

(c) Copyright is held by the authors.

Working papers of the Max Planck Institute for Demographic Research receive only limited review. Views or opinions expressed in working papers are attributable to the authors and do not necessarily reflect those of the Institute. 


\title{
Age-Structured Optimal Control in Population Economics $^{1}$
}

\author{
Gustav Feichtinger ${ }^{2}$, Alexia Prskawetz ${ }^{3}$, and Vladimir M. Veliov ${ }^{4}$
}

\begin{abstract}
This paper brings both intertemporal and age-dependent features to a theory of population policy at the macro-level. A Lotka-type renewal model of population dynamics is combined with a Solow/Ramsey economy. By using a new maximum principle for distributed parameter control we derive meaningful qualitative results for the optimal migration path and the optimal saving rate.
\end{abstract}

\footnotetext{
${ }^{1}$ This research was partly supported by the Austrian Science Foundation under contract N0. 14060-OEK.

The authors are grateful for comments and suggestion by Thomas Lindh and Ross Guest and participants at the session on Population and Macroeconomics at the PAA 2002 meeting in Atlanta. For language editing, we would like to thank Renee Flibotte.

${ }^{2}$ Institute for Econometrics, Operations Research and Systems Theory, Vienna University of Technology, Argentinierstrasse 8/119, A-1040 Vienna, Austria, e-mail: or@e119ws1.tuwien.ac.at

${ }^{3}$ MPI for Demographic Research, Doberanerstr. 114, 18057 Rostock, Germany, e-mail: fuernkranz@demogr.mpg.de; the views expressed in this paper are my own views and do not necessarily represent those of the Max Planck Institute for Demographic Research.

${ }^{4}$ Institute for Econometrics, Operations Research and Systems Theory, Vienna University of Technology, Argentinierstrasse 8/119, A-1040 Vienna, Austria and Institute of Mathematics and Informatics, Bulgarian Academy of Sciences, 1113 Sofia, Bulgaria, e-mail: vveliov@eos.tuwien.ac.at
} 


\section{Introduction}

In this paper we present an approach for dynamic optimization in population economics which is based on an optimal control model involving age-structured differential equations for the dynamics of both the population and the capital. In the qualitative analysis and in the numerical solution of the problem we utilize the newly derived maximum principle for age-structured systems (Feichtinger et al., 2000). It is shown how the necessary optimality conditions may be used to derive interesting insights into the structure of efficient age-dependent policies to cope with demo-economic problems arising in ageing populations.

We mention that age or duration play an important role in many models in biology, economics and in the social sphere, where one can apply the maximum principle from Feichtinger et al. (2000) or its extension in Feichtinger et al. (2002) (concerning systems that involve simultaneously age and duration). An extensive bibliography is presented in Feichtinger et al. (2000).

Age is ubiquitous in demography. Virtually all demographic variables depend on age. The core of population dynamics, stable population theory, is centered on age. In economics, capital vintage models play a certain role (see, e.g., Solow, 1959), but agedependence of stocks and flows seems - for whatever reasons - to be not mainstream.

In an important early contribution, Arthur and McNicoll (1977) included age-dependent features both of the population as well as of the capital stock. In their approach a one-sex renewal-type population in the sense of Lotka is combined with a one-good Solow-type economy. By assuming a capital vintage approach, a certain symmetry arises between the population and the economic sector. Corresponding to the birth rate and the birth trajectory are the savings rate and investment, with the fertility level and the savings rate considered as control variables. The fact that these processes evolve along a dimension of age as well as time makes the analysis difficult. To investigate the resulting optimal control problems, Arthur and McNicoll utilize results from control theory of integral equations, see Vinokurov (1969), which are applicable for age-independent controls.

In the present paper the Arthur-McNicoll model is extended in several directions. First we consider the savings control to be age-dependent. Second, (and this is related to the age-dependency of the savings rate) we consider an age-dependent distribution of the total output produced in the economy among the members of the society, defined by a given income profile. Third, in contrast to the Arthur-McNicoll model, our model is balanced: "consumption" + "investment" + "control cost" = "production". Fourth, 
the more general form of the model, involving distributed differential and integral equations (rather than Volterra integral equations) allows a number of extensions in diverse directions. Here we include migration as an additional control inflow (which, in fact is a most efficient control instrument for many countries, see Guest and McDonald (2002). Unlike Arthur and McNicoll, we assume that fertility cannot be controlled. Finally, stimulated by the paper by Cutler et al. (1990) we take into account the role played by technological progress in mitigating the impact of an aging population.

The paper is organized as follows. In section 2 we present the model and its assumptions. Section 3 summarizes the parameterization of our model and gives a first insight into the system's dynamics for alternative (age-independent) future scenarios of technological progress. Initial age schedules of demographic and economic variables are taken from Austria, except for the savings rate where we refer to German data sources. By calibrating our model to current demographic and economic variables of an industrialized country our paper adds to the growing literature on optimal economic and demographic responses in an aging society (see e.g. Cutler et al., 1990, Guest and McDonald, 2002). Necessary optimality conditions in the form of Pontryagin's maximum principle utilizing a recent general result in Feichtinger et al. (2000) are obtained in Section 4. We mention that the earlier general maximum principle by Brokate (1985) is formally not applicable due to the presence of boundary control in the economic component of our model. In Section 5 we present numerical solutions of the optimal age- dependent savings and migration rates applying the numerical method and respective software for general age-structured systems developed recently by the third author. We close with some conclusions and suggestions for further research (Section 6).

\section{Description of the Model}

We describe both the dynamics of the population and of the physical capital stock with the McKendrick equations (Keyfitz and Keyfitz, 1997)

$$
\begin{aligned}
N_{t}+N_{a} & =-\mu(t, a) N(t, a)+\nu(t, a), & & N(0, a)=N_{0}(a), N(t, 0)=B(t), \\
K_{t}+K_{a} & =-\delta(t, a) K(t, a), & & K(0, a)=K_{0}(a), K(t, 0)=I(t), \\
B(t) & =\int_{0}^{\omega} f(t, a) N(t, a) \mathrm{d} a . & &
\end{aligned}
$$

Here the state variables are 
$N(t, a)$ - number of people of age $a$ at time $t$,

$K(t, a)$ - physical capital stock of age $a$ at time $t$,

$B(t)$ - newborn individuals at time $t$,

$I(t)$ - investment in capital goods at time $t$.

Moreover, $\mu(t, a)$ and $\delta(t, a)$ are the mortality rate of individuals and the depreciation rate of physical capital, respectively. The function $f(t, a)$ represents the fertility rate of $a$-year old individuals at time $t$.

The (net) migration $\nu(t, a)$ is considered as a control variable subject to the constraint $\nu(t, a) \geq 0$. It is reasonable, however, to assume that the age-distribution of the migration is fixed (at the present level, for example - see Figure 5, Section 3) and only its magnitude can be actually controlled. That is, we suppose that $\nu(t, a)=\nu(t) \nu_{0}(a)$, where $\nu_{0}(a)$ is a given function such that $\int_{0}^{\omega} \nu_{0}(a) \mathrm{d} a=1$, and $\nu(t) \in[0, \bar{\nu}(t)]$ is a control, restricted by a given upper bound $\bar{\nu}(t)$.

The number $\omega$ represents a maximal age. Presumably, the support of $f(t, \cdot)$ is a subinterval of $[0, \omega]$. Similarly, the number $\kappa$ below is the maximal age of the physical capital goods: machines of age $\kappa$ are scraped. We assume $\kappa$ to be exogenously given. ${ }^{5}$

We take the control costs into account as one component of the total expenditures, the other two being consumption and investment.

More precisely, the savings is split between investment in production capital and costs of migration control. ${ }^{6}$

Let $\tilde{S}(t)$ be the savings at time $t$, and $G(t)$ be the part of it spent on migration control. Assuming a closed economy, investment into new capital $K(t, 0)$ is then given by $I(t)=\tilde{S}(t)-G(t)$. With $m(t, \nu)$ denoting the 'adjustment' costs for $\nu$ new immigrants (distributed among ages as $\left.\nu_{0}(\cdot)\right)$ per unit of time, then $G(t)=m(t, \nu(t))$.

To 'close' the model one has to analyze the amount of savings.

Let $y(t, a)$ be the per capita income of the a-year old individuals. The $a$-year old individuals save a fraction $\sigma(t, a) \in[0, \bar{\sigma}(t, a)]$ of the income which will be considered

\footnotetext{
${ }^{5}$ Alternatively one may assume $\kappa$ to be endogenously determined within the framework of a putty-clay production technology (see Guest and McDonald, 2002 and Lindh, 2000).

${ }^{6}$ Other possibilities are to take the control costs from the total income, reducing in this way the net income, or from the consumption. The corresponding models would be slightly different from the one described below.
} 
as another control variable. Here $\bar{\sigma}(t, a)$ is an age-specific upper bound on the savings rate. We do not associate control costs with the savings control since it has no normative meaning.

We have

$$
\tilde{S}(t)=\int_{0}^{\omega} \sigma(t, a) y(t, a) N(t, a) \mathrm{d} a .
$$

The total income at $t$ equals the production $Y(t)$ :

$$
\int_{0}^{\omega} y(t, a) N(t, a) \mathrm{d} a=Y(t) .
$$

We suppose that the distribution of the product among the individuals is age (and time) dependent. Let $d(t, \cdot)$ be the income profile at $t$. That is, $y(t, a) / y(t, \bar{a})=$ $d(t, a) / d(t, \bar{a})$ for every $a$ and $\bar{a}$ (cf. Figure 3 , Section 3). ${ }^{7}$ If we fix some reference age $\bar{a}$ (say, $\bar{a}=45$ years) we may express

$$
y(t, a)=d(t, a) \bar{y}(t), \quad \text { where } \bar{y}(t)=y(t, \bar{a}) / d(t, \bar{a}) .
$$

Then from (1) we obtain

$$
\bar{y}(t) \int_{0}^{\omega} d(t, a) N(t, a) \mathrm{d} a=Y(t)
$$

and

$$
\bar{y}(t)=\frac{Y(t)}{E(t)}
$$

where

$$
E(t)=\int_{0}^{\omega} d(t, a) N(t, a) \mathrm{d} a
$$

is the aggregate relative income (so that $E(t) \bar{y}(t)$ is the total income of the population). Thus we obtain the following expression for the per capita income:

$$
y(t, a)=d(t, a) \frac{Y(t)}{E(t)} .
$$

Then for the savings we have

$$
\tilde{S}(t)=\int_{0}^{\omega} \sigma(t, a) N(t, a) d(t, a) \mathrm{d} a Y(t) / E(t)=S(t) \frac{Y(t)}{E(t)},
$$

\footnotetext{
${ }^{7}$ In Figure 3 we assumed the normalization $d(t, \bar{a})=1$. However other normalizations like $\int_{0}^{\omega} d(a) d a=1$ are possible as well.
} 
where

$$
S(t)=\int_{0}^{\omega} \sigma(t, a) N(t, a) d(t, a) \mathrm{d} a
$$

is the aggregate relative savings, so that $S(t) \bar{y}(t)$ is the total savings $\tilde{S}(t)$, and $S(t) / E(t)$ is the actual savings rate: $\tilde{S}(t)=S(t) Y(t) / E(t)$.

Finally, the production is supposed to be a function of the total production capacity $P(t)$ and the labor stock $L(t)$ :

$$
Y(t)=F(P(t), L(t), t),
$$

where

$$
\begin{aligned}
P(t) & =\int_{0}^{\kappa} p(t, a) K(t, a) \mathrm{d} a, \\
L(t) & =\int_{0}^{\omega} q(t, a) l(t, a) N(t, a) \mathrm{d} a,
\end{aligned}
$$

$p(t, a)$ is the productivity of $a$-year old machines at time $t, l(t, a)$ is the fraction of the employed individuals among all individuals of age $a$ (cf. Figure 2, Section 3), and $q(t, a)$ is the qualification factor of the labor of age $a$. Notice that it makes sense to take the function $p(t, a)$ of the form $p(t, a)=p(a) r(t-a)$ with $p(a)$ decreasing and $r(h)$ increasing in its argument. The first factor reflects the drop of productivity (depreciation) with age, while the second factor reflects the technological progress: for machines at any fixed age, those of later vintage, $t-a$, are more productive. We assume technological progress to be exogenously given.

Summarizing, we obtain the following dynamic control model:

$$
\begin{aligned}
N_{t}+N_{a} & =-\mu(t, a) N(t, a)+\nu(t) \nu_{0}(a), \quad N(0, a)=N_{0}(a), \quad N(t, 0)=B(t), \\
K_{t}+K_{a} & =-\delta(t, a) K(t, a), \quad K(0, a)=K_{0}(a), \quad K(t, 0)=\tilde{S}(t)-m(t, \nu(t)), \\
B(t) & =\int_{0}^{\omega} f(t, a) N(t, a) \mathrm{d} a, \\
P(t) & =\int_{0}^{\kappa} p(t, a) K(t, a) \mathrm{d} a, \\
L(t) & =\int_{0}^{\omega} q(t, a) l(t, a) N(t, a) \mathrm{d} a, \\
E(t) & =\int_{0}^{\omega} d(t, a) N(t, a) \mathrm{d} a, \\
S(t) & =\int_{0}^{\omega} \sigma(t, a) d(t, a) N(t, a) \mathrm{d} a \\
M(t) & =\int_{0}^{\omega} N(t, a) \mathrm{d} a,
\end{aligned}
$$


where the last equation is added since the total number of people, $M(t)$, will be used in the objective function. Here we consider $N, K, B, P, L, E, S, M$ as state variables and $\sigma(t, a) \in[0, \bar{\sigma}(t, a)]$ and $\nu(t) \in[0, \bar{\nu}(t)]$ as control variables. $N_{0}, K_{0}, \mu, \delta, F, f, p, l, m, d$ are exogenously given functions. The savings $\tilde{S}(t)$ in the boundary conditions for $K$ is related to the state variables according to the formula

$$
\tilde{S}(t)=S(t) \frac{F(P(t), L(t), t)}{E(t)} .
$$

The objective function of the social planner is to maximize the social welfare

$$
\int_{0}^{T} e^{-r t} \int_{0}^{\omega} W(t, a, c(t, a)) \frac{N(t, a)}{M(t)} \mathrm{d} a \mathrm{~d} t
$$

(the case $T=+\infty$ is not excluded) where $c(t, a)$ stays for the per capita consumption at time $t$ of the $a$-years old individuals:

$$
c(t, a)=(1-\sigma(t, a)) y(t, a){ }^{8}
$$

Remember that the income at age $a$ is given by

$$
y(t, a)=d(t, a) \frac{F(P(t), L(t), t)}{E(t)} .
$$

Thus, in the objective function we maximize the discounted integral of the weighted average per capita welfare, the latter being a function of the individual consumption. The weights of the different ages are proportional to the percentage of people at the given age. ${ }^{9}$

\section{Parameterization and Numerical Simulations}

For all subsequent numerical simulations we initialize the age structure of economic and demographic variables referring to Austrian data as of 1999 (1998). The agespecific savings profile is taken from Germany. The Austrian population is a valid

\footnotetext{
${ }^{8}$ The children's income taken into account in the income profile does not include the transfer from parents. Therefore the children's welfare is underestimated, while that of the parents is overestimated. In fact, we implicitly assume that one unit of consumption yields the same marginal utility for the family as a whole, independently of whether it is spent by the children or by their parents.

${ }^{9}$ If the weight $d(t, a) N(t, a) / E(t)$ is used instead of $N(t, a) / M(t)$, which means that not only the percentage of the people of a given age is taken into account, but also their "reputation", represented by their relative income $d(t, a)$, then the variable $M(t)$ is no longer in use and can be omitted.
} 
example of an aging society with the challenges and opportunities for demographic and economic developments as discussed in e.g. Cutler et al. (1990) .

More specifically, we assume the following specification:

$$
\begin{aligned}
& \mu(t, a)=\mu(a) \text { data for Austria, } 1999 \text { (Figure 1), } \\
& \delta(t, a)=\delta=0.06 \\
& f(t, a)=f(a) \text { data for Austria, } 1999 \text { (Figure 1), } \\
& \nu_{0}(a) \text { data for Austria, } 1999 \text { (Figure 5), } \\
& \sigma(t, a)=\sigma(a) \text { data for Germany, } 1998 \text { (Figure 4) })^{10} \text {, } \\
& p(t, a)=q_{0}+g_{t} t+g_{a} a ; q_{0}=7.5, g_{a}=-0.1, g_{t}=0.02 \text {, } \\
& l(t, a)=l(a) \text { data for Austria, } 1999 \text { (Figure 2), } \\
& d(t, a)=d(a) \text { data for Austria, } 1998 \text { (Figure 3), } \\
& q(t, a)=d(a) \text { data for Austria, } 1998 \text { (Figure 3) }{ }^{11} \text {, } \\
& N_{0}(a) \text { data for Austria, } 1999 \text { (Figure 2), } \\
& K_{0}(a)=K_{0} e^{-\delta a} / \int_{0}^{\kappa} e^{-\delta t} \mathrm{~d} t=\frac{K_{0}}{13.912} e^{-\delta a}, K_{0}=100,000 \text {, } \\
& F(P, L, t)=c P^{0.34} L^{0.66}, c=3.5 \text {, } \\
& W(t, a, C)=[c(t, a) / u(a)]^{\alpha} \text { where } u(a) \text { is taken from Cutler et al. (1990, p.9) and } \\
& \text { represents effective consumption needs (see Table } 1 \text { ), and } \\
& \alpha \in(0,1] \text { is the consumption elasticity of the welfare. }
\end{aligned}
$$

The relative consumption needs $u(a)$ are derived by considering three components (private nonmedical expenses, public education expenses, and medical care), and represent the relative demands for consumption of different age groups. E.g. young people consume less private consumption but more education whereas older people consume more health services. By weighting consumption at age $a$ and time $t, c(t, a)$. With these relative consumption weights we are taking care that the same level of consumption gives different levels of utility across ages. Consequently, for a given age schedule of consumption levels, a population with higher shares of people in ages of higher relative consumption demands (as happens when the population ages) will experience lower welfare. However, since consumption levels are determined by the

\footnotetext{
${ }^{10}$ On the German savings puzzle (savings rates are high and stable until the 40s and remain positive in old age) see Börsch-Supan (2002).

${ }^{11}$ Our assumption that the age distribution of earnings reflect the age distribution of labor productivity is similar to Guest and McDonald (2002, p. 8).
} 

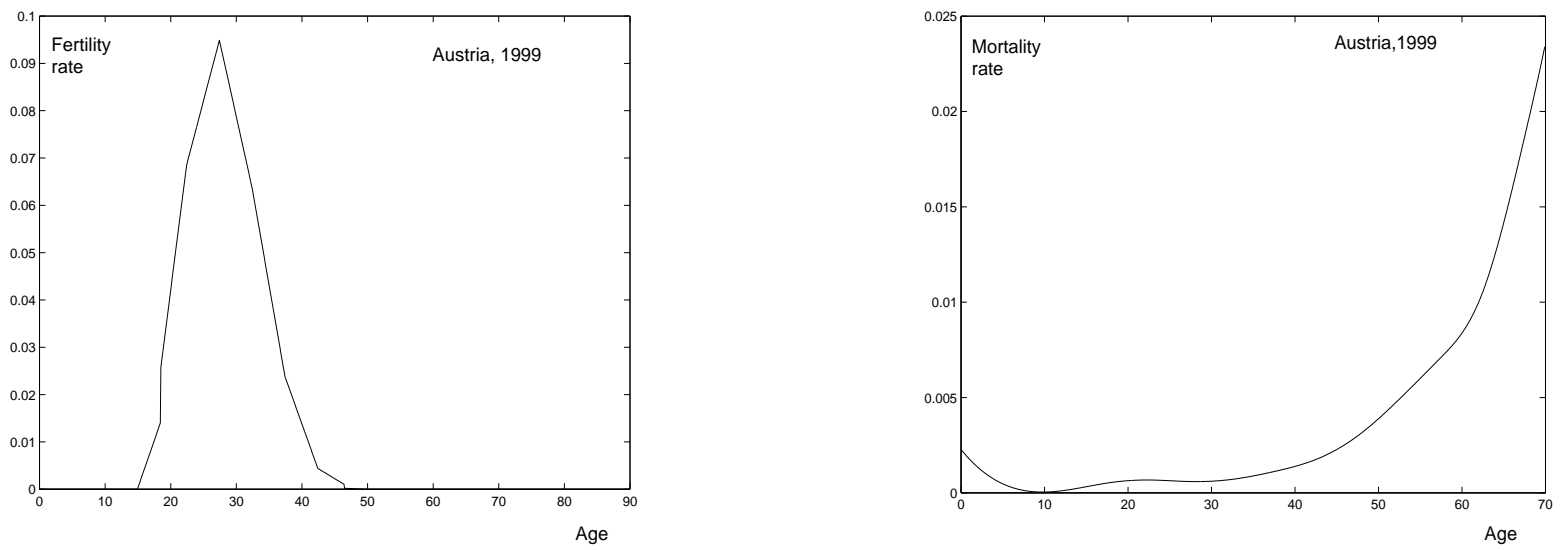

Figure 1: Fertility rate $f(a)$ (left) and mortality rate, $\mu(a)$ (right); Austria 1999. The specific age schedule of fertility rates corresponds to a total fertility rate of 1.32 children, while the age schedule of mortality rates corresponds to a life expectancy of $e_{0}=74$ years.

macro-economic and demographic developments, aging does not need to imply lower welfare if age specific levels of consumption change.

Furthermore, the current productivity of the capital $q_{0}$ is determined in such a way that if all exogenous factors do not change and if the current population stayed the same at every age (that is, the population is at equilibrium), then the capital, therefore the welfare, would be at equilibrium as well.

Table 1: Age profile of $u(a)$.

\begin{tabular}{l|rrr}
\hline Age group & $0-19$ & $20-64$ & $>64$ \\
\hline consumption weight & 0.72 & 1.00 & 1.27 \\
\hline
\end{tabular}

Before introducing the optimization w.r.t. savings and migration (Section 4) we briefly present simulations of our model if current demographic and economic trends prevail for the next 100 years. In Section 5 we shall refer to these benchmark simulations when we discuss numerical solutions of the optimal time paths of savings and migration. We assume that the agespecific fertility, mortality and migration schedules of Austria in 1999 will stay the same in the future and we set costs of migration $m(\nu)$ equal to zero. However, we allow for technological progress and plot two alternative scenarios $\left(g_{t}=0.02\right.$ and $\left.g_{t}=0.04\right)$ in addition to the baseline scenario where we assume zero technological progress $\left(g_{t}=0\right)$. In Figure 6 , Figure 7 and Figure 8 we plot the level of welfare $^{12}$, population shares in three age groups, investment and productive capacity

\footnotetext{
${ }^{12}$ We disregard discounting and plot for each time step the level of welfare: $\int_{0}^{\omega} \frac{c(t, a)}{u(a)} \frac{N(t, a)}{M(t)} \mathrm{d} a$
} 

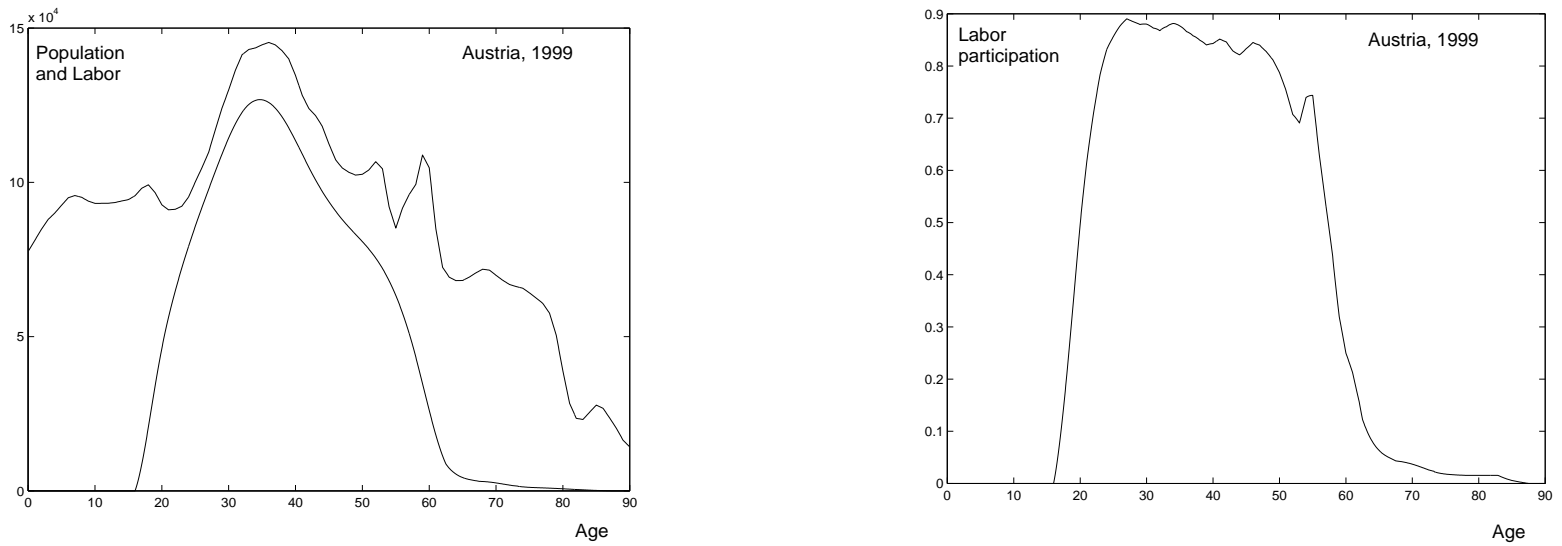

Figure 2: Distribution of the population and the economically active individuals (left) and the labor force participation rate (right); Austria 1999.

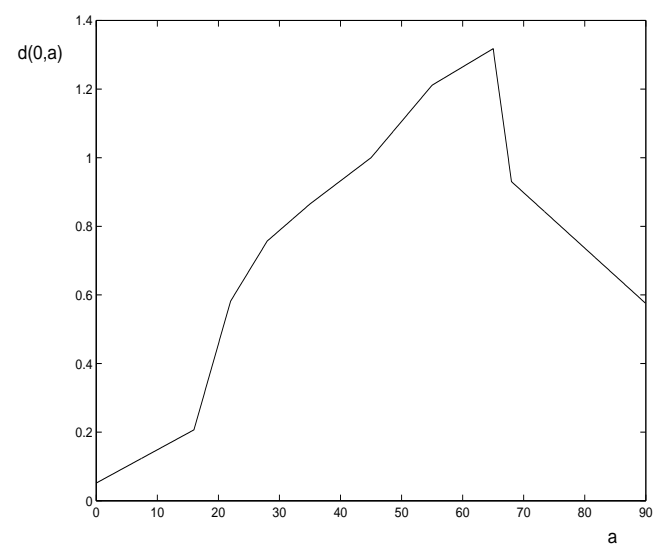

Figure 3: Income profile $d(a)$; Austria, 1998, based on monthly gross income of employees by age groups.

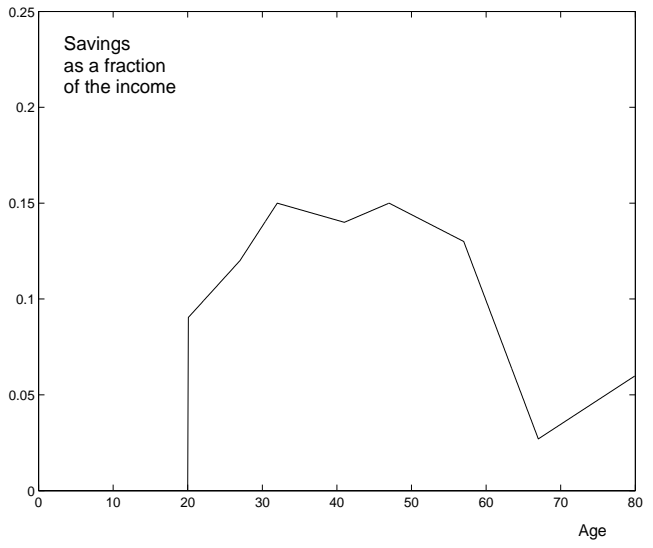

Figure 4: Private savings $\sigma(a)$ as a fraction of the income; Germany 1998. 


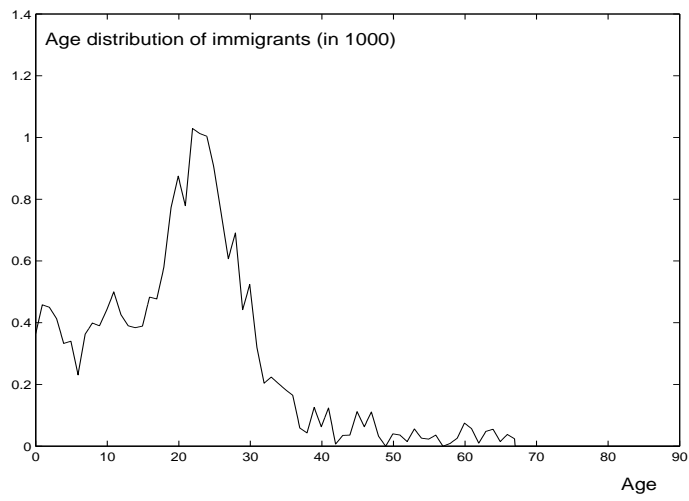

Figure 5: Migration $\nu(a)$; Austria 1999.

for the next 100 years.

The evolution of the welfare index is mainly driven by the ageing of the baby boom generation. During the first two decades of the 21st century smaller cohorts will be entering the labor force while the baby boom generation has not yet retired. Consequently the share of people in their productive ages is still high (right panel of Figure 7) while continued low levels of fertility imply a decrease in the share of young people and an increase in the share of old people (left panel of Figure 7). For the subsequent two decades, when the baby boomers start to retire, we will observe a pronounced increase in the share of the population aged 65 and a drastic reduction in the share of people in the labor force. This demographic development is mirrored in an increase in the welfare during the first 20 years of our simulation which is followed by a decline of the welfare (even if we allow for technological progress) for the subsequent 20 years (Figure 6). Obviously the retirement of the baby boom generation will lead to a pronounced decline in aggregate savings (=investments, Figure 8$)^{13}$ and consequently the productive capacity will decrease if we neglect technological progress (Figure 8). Note that, since the number of workers decreases, productive capacity per labor unit will stay constant even when we assume no technological progress. Together, the fall in the share of the labor force and the reduced production capacity will lead to a lower level of income and hence consumption per capita will decline. ${ }^{14}$ The decline in

\footnotetext{
${ }^{13}$ Note that the decline in aggregate savings follows from the change in the population age structure which becomes more concentrated towards people at higher ages who have lower savings. This result is different from the 'Solow' effect (see Cutler et al., 1990) which states that the slower labor force growth reduces investment requirements and hence reduces the needs for savings and may therefore increase consumption per capita.

${ }^{14}$ Similar to Cutler et al. (1990) the latter effect is identical to the negative dependency effect.
} 
welfare comes to a halt around the late $30 \mathrm{~s}$ if we assume no technological progress. In case of technological progress we observe an earlier leveling off for the welfare that turns into an increase of welfare during the early $30 \mathrm{~s}^{15}$ The leveling off of the welfare may be explained by the gradual decease of the baby boom generation which leads to a stabilization of the share of old people at a value of about $24 \%$. As evidenced in Figure 8 , the potential of technological progress allows productive capacity to grow even though investment continues to decline as the population ages. Hence, aging of the population need not imply a reduction in welfare in the long run if we account for technological progress. However, during the transition period when the cohort of baby boomers retires, a reduction in welfare will most likely occur except for very high levels of productivity growth. Since we keep fertility, mortality and migration flows constant we approach a stable age distribution in the long run with the population continuously declining from around 8 million in 1999 to 5 million within the time span of our simulations.

As the numerical experiment illustrates, the dynamics of the welfare is rather complex and it is difficult to predict the outcome of the combined effect of alternative migration and savings policies. In particular, it is rather difficult to experiment as to what an optimal control may look like, particularly if one allowed for age dependency as is definitely imperative if we consider alternative migration and savings scenarios. We therefore need to formalize the intertemporal optimization and apply the maximum principle to find the optimal, age-dependent schedules of migration and savings. We proceed with the economic interpretations of the maximum principle in the next section and present numerical paths of the optimal migration and savings in Section 5 .

\section{Maximum Principle: Economic Interpretations}

\subsection{Formulation of the Maximum Principle}

Below we apply the general result from Feichtinger et al. (2000) to obtain a necessary optimality condition in the form of a maximum principle.

Let $\hat{K}, \ldots, \hat{S}, \hat{\sigma}, \hat{\nu}$ be an optimal solution. For convenience we denote

$$
U(t, a, N, P, L, E, M, \sigma)=W(t, a,(1-\sigma) d(t, a) F(t, P, L) / E) N / M,
$$

Since our model does not allow for the positive Solow effect, the aging of the population will always depress welfare if technological progress is not taken into account.

${ }^{15}$ These results are in accordance with the argument in Cutler et al. (1990) who states that 'a decline in living standards caused by an increase in dependency would be fully reversed by a $0.15 \%$ a year increase in productivity growth' (Cutler et al., 1990,p.3). 


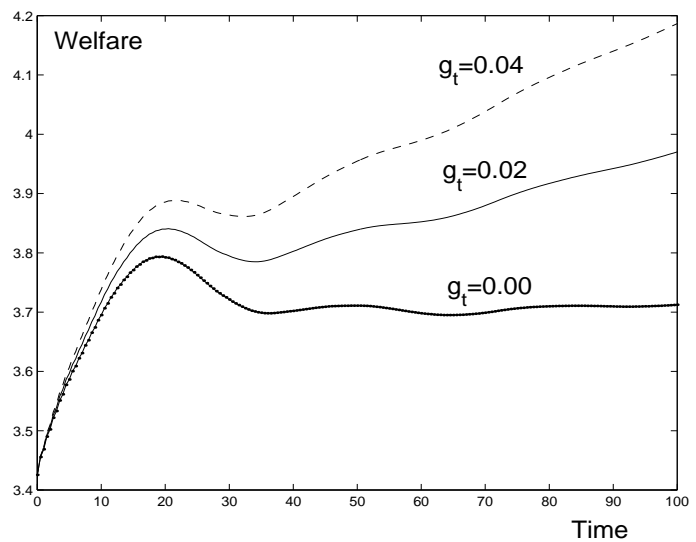

Figure 6: Aggregate welfare if demographic parameters are kept constant at their 1999 values and if technological progress takes place.
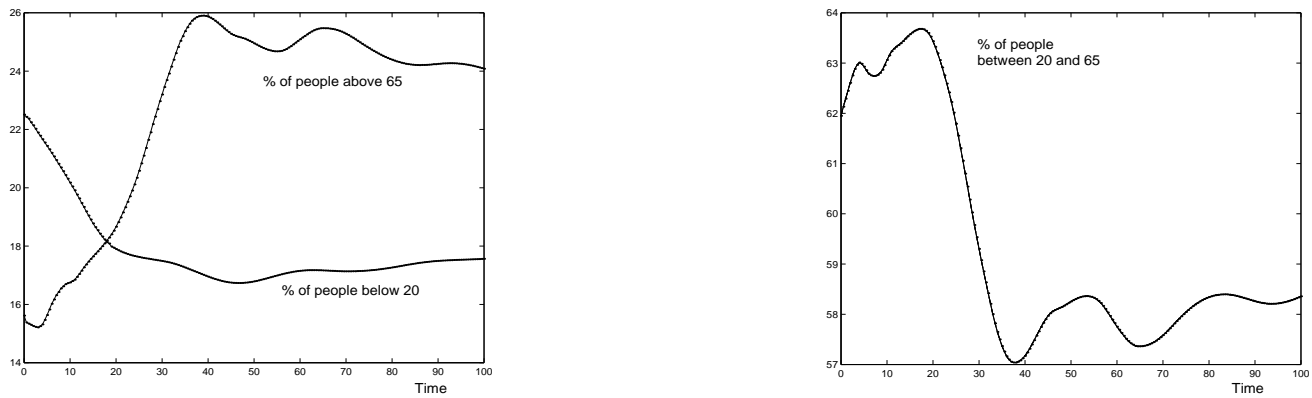

Figure 7: Share of young and old aged individuals (left) and share of the labor force (right) for the three scenarios presented in Figure 6.
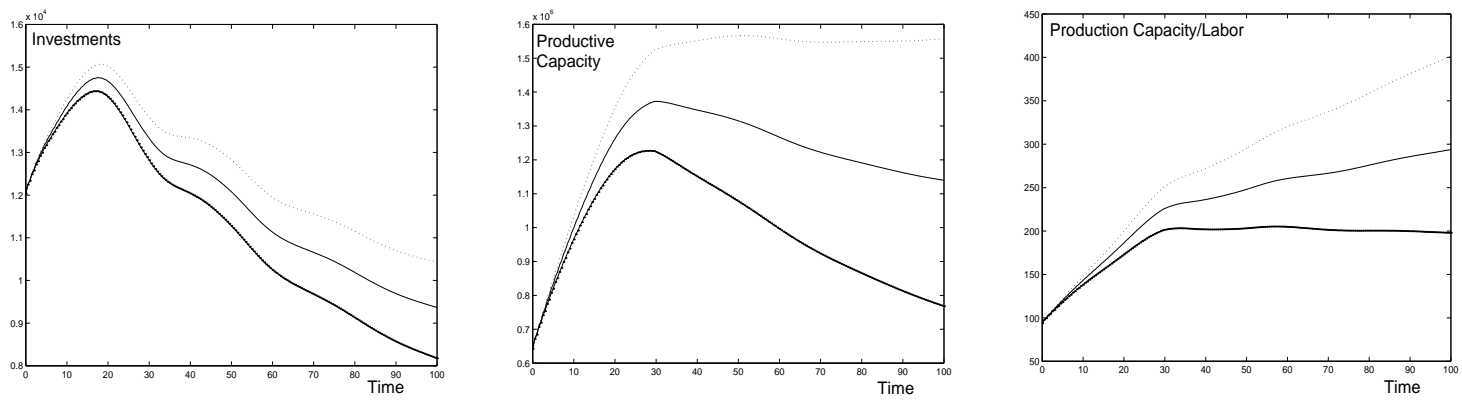

Figure 8: Stock of investment (left), productive capacity (middle) and productive capacity per labor unit for the three scenarios presented in Figure 6. 
which is the instantaneous utility (weighted by the relative share of people in each age group $N(t, a) / M(t))$ at time $t$ of the $a$-year old individuals. Thus the objective function can be written as

$$
\int_{0}^{T} e^{-r t} \int_{0}^{\omega} U(t, a, N(t, a), P(t), L(t), E(t), M(t), \sigma(t, a)) \mathrm{d} a \mathrm{~d} t .
$$

In the considerations below we may assume this more general form for the objective function, but occasionally we simplify the formulas using the particular form (2).

Below we use the following notational convention: in the functions $F, W$ and $U$ we skip the arguments with "^". For example, $F(t)=F(t, \hat{P}(t), \hat{L}(t)), U(t, a, \sigma)=$ $U(t, a, \hat{N}(t, a), \hat{P}(t), \hat{L}(t), \hat{E}(t), \hat{M}(t), \sigma)$.

Applying the maximum principle from Feichtinger et al. (2000) and changing the dual variables as ". $\longrightarrow-e^{r t}$." (passing in this way to current value) we obtain the following:

Maximum principle: there exist adjoint variables $\xi^{N}(t, a), \xi^{K}(t, a)$ (corresponding to the differential equations of $N$ and $K)$, and $\zeta^{B}(t), \zeta^{P}(t), \zeta^{L}(t), \zeta^{E}(t), \zeta^{S(t)}, \zeta^{M}(t)$ (corresponding to the state variables $B(t), P(t), L(t), E(t), S(t), M(t)$ ) satisfying the equations

$$
\begin{aligned}
\xi_{t}^{N}+\xi_{a}^{N}= & (\mu(t, a)+r) \xi^{N}(t, a)-f(t, a) \zeta^{B}(t)-q(t, a) l(t, a) \zeta^{L}(t) \\
& -d(t, a) \zeta^{E}(t)-\hat{\sigma}(t, a) d(t, a) \zeta^{S(t)}-\zeta^{M}(t)-U_{N}(t, a), \quad \xi^{N}(t, \omega)=0 \\
\xi_{t}^{K}+\xi_{a}^{K}= & (\delta(t, a)+r) \xi^{K}(t, a)-p(t, a) \zeta^{P}(t), \quad \xi^{K}(t, \omega)=0, \\
\zeta^{B}(t)= & \xi^{N}(t, 0), \\
\zeta^{P}(t)= & \xi^{K}(t, 0) F_{P}(t) \hat{S}(t) / \hat{E}(t)+\int_{0}^{\omega} U_{P}(t, a) \mathrm{d} a \\
\zeta^{L}(t)= & \xi^{K}(t, 0) F_{L}(t) \hat{S}(t) / \hat{E}(t)+\int_{0}^{\omega} U_{L}(t, a) \mathrm{d} a \\
\zeta^{E}(t)= & -\xi^{K}(t, 0) F(t) \hat{S}(t) / \hat{E}(t)^{2}+\int_{0}^{\omega} U_{E}(t, a) \mathrm{d} a \\
\zeta^{S}(t)= & \xi^{K}(t, 0) F(t) / \hat{E}(t), \\
\zeta^{M}(t)= & \int_{0}^{\omega} U_{M}(t, a) \mathrm{d} a
\end{aligned}
$$

such that the optimal controls $\hat{\sigma}(t, a)$ and $\hat{\nu}(t)$ maximize the function

$$
\begin{gathered}
(\sigma, \nu) \longrightarrow \\
U(t, a, \sigma)+\sigma \zeta^{S}(t) d(t, a) \hat{N}(t, a)+\int_{0}^{\omega} \xi^{N}(t, a) \nu_{0}(a) \mathrm{d} a \nu-\xi^{K}(t, 0) m(t, \nu)
\end{gathered}
$$


which splits into two independent maximization conditions.

For brevity we denote

$$
\begin{aligned}
V^{P}(t) & =\int_{0}^{\omega} U_{P}(t, a) \mathrm{d} a, \quad V^{L}(t)=\int_{0}^{\omega} U_{L}(t, a) \mathrm{d} a \\
V^{E}(t) & =\int_{0}^{\omega} U_{E}(t, a) \mathrm{d} a, \quad V^{M}(t)=\int_{0}^{\omega} U_{M}(t, a) \mathrm{d} a,
\end{aligned}
$$

and also

$$
\begin{gathered}
\tilde{S}_{P}(t)=F_{P}(t) \hat{S}(t) / \hat{E}(t), \quad \tilde{S}_{L}(t)=F_{L}(t) \hat{S}(t) / \hat{E}(t), \\
\tilde{S}_{E}(t)=-F(t) \hat{S}(t) / \hat{E}(t)^{2}, \quad \tilde{S}_{S}(t)=F(t) / \hat{E}(t) .
\end{gathered}
$$

Note that $\tilde{S}_{P}, \tilde{S}_{L}, \tilde{S}_{E}$ and $\tilde{S}_{S}$ are exactly the corresponding derivatives of the total savings $\tilde{S}$, which justifies the notations. Excluding all $\zeta$-variables for $\xi^{K}$ and $\xi^{N}$ we obtain the equations

$$
\begin{aligned}
\xi_{t}^{N}+\xi_{a}^{N}= & (\mu(t, a)+r) \xi^{N}(t, a)-\hat{f}(t, a) \xi^{N}(t, 0) \\
& -\xi^{K}(t, 0)\left[q(t, a) l(t, a) \tilde{S}_{L}(t)+d(t, a) \tilde{S}_{E}(t)+\hat{\sigma}(t, a) d(t, a) \tilde{S}_{S}(t)\right] \\
& -q(t, a) l(t, a) V^{L}(t)-d(t, a) V^{E}(t)-V^{M}(t)-U_{N}(t, a), \\
\xi_{t}^{K}+\xi_{a}^{K}= & (\delta(t, a)+r) \xi^{K}(t, a)-p(t, a) \xi^{K}(t, 0) \tilde{S}_{P}(t)-p(t, a) V^{P}(t)
\end{aligned}
$$

with zero side conditions at $a=\omega$ and $t=T$. The maximum condition (3) gives the variational inequalities

$$
\begin{gathered}
{\left[U_{\sigma}(t, a, \sigma)+\xi^{K}(t, 0) \hat{y}(t, a) \hat{N}(t, a)\right](\sigma-\hat{\sigma}) \leq 0 \quad \forall \sigma \in[0, \bar{\sigma}(t, a)],} \\
{\left[\int_{0}^{\omega} \xi^{N}(t, a) \nu_{0}(a) \mathrm{d} a-\xi^{K}(t, 0) m_{\nu}(t, \hat{\nu})\right](\nu-\hat{\nu}) \leq 0 \quad \forall \nu \in[0, \bar{\nu}(t)] .}
\end{gathered}
$$

Note that condition (6) simplifies if we take the specific form of the objective function into account. We have

$$
U_{\sigma}(t, a, \sigma)=-W_{c}(t, a,(1-\sigma) \hat{y}(t, a)) \hat{y}(t, a) \frac{\hat{N}(t, a)}{\hat{M}(t)},
$$

and (6) reduces to

$$
\left[-W_{c}(t, a,(1-\sigma) \hat{y}(t, a)) \frac{1}{\hat{M}(t)}+\xi^{K}(t, 0)\right](\sigma-\hat{\sigma}) \leq 0 \quad \forall \sigma \in[0, \bar{\sigma}(t, a)] .
$$




\subsection{Economic Interpretations}

To give an economic interpretation of the maximum principle we first notice that $\xi^{N}(t, a)$ is the current marginal value of a single individual of age $a$ at time $t$; that is, the total change of welfare (discounted starting from $t$ ) due to a unit change of $\hat{N}(t, a)$ at time $t$

$\xi^{K}(t, a)$ is the current marginal value of a unit of capital of age $a$ at time $t$; that is, the total change of welfare (discounted starting from $t$ ) due to a marginal unit change of $\hat{K}(t, a)$ at time $t$;

Consequently, $\xi^{N}(t, 0)$ and $\xi^{K}(t, 0)$ are the marginal value of a new-born individual and of a unit of investment, respectively. Notice that the above values are measured in terms of units of welfare.

Then the maximization conditions (6) and (7) assert the following (wherever the control constraints are not active):

(6): the direct marginal welfare cost $\left(-U_{\sigma}(t, a, \sigma)\right)$ of an additional percent of income allocated for savings by the $a$-year olds equals

the marginal welfare benefit if this percent is invested in new capital; the latter value is represented by $\xi^{K}(t, 0) \hat{y}(t, a) \hat{N}(t, a)$ - the value of a unit of a new capital times the total additional investments done by $a$-year old people, if the savings rate is increased by one percent;

(7): the marginal opportunity cost of the spending necessary for an additional immigrant of age $a$ (that is, the additional welfare $\xi^{K}(t, 0) m_{\nu}(t, \nu)$ that could be obtained by investing this spending in new capital) equals the value of an individual of age $a$.

To interpret the adjoint equations we shall clarify the meaning of the individual terms. First of all

$\tilde{S}_{P}(t)$ - the additional savings per unit of time, resulting from an additional unit of productive capacity at the margin;

$\tilde{S}_{P}(t) p(t, a)$ - the additional savings per unit of time, resulting from an additional unit of capital of age $a$ due to the higher productive capacity;

$\xi^{K}(t, 0) \tilde{S}_{P}(t) p(t, a)$ - value of the additional capital created by investing the additional savings per unit of time, resulting from an additional unit of capital used a unit of time at the margin. 
Similarly we obtain the meaning of the other terms:

$p(t, a) V_{P}(t)$ - additional welfare gained per unit of time, directly from the consumed part of the additional production resulting from an additional unit of capital used a unit of time at the margin;

$\xi^{N}(t, 0) f(t, a)$ - value of the additional population created per unit of time, by an additional member of the population of age $a$;

$\xi^{K}(t, 0) q(t, a) l(t, a) \tilde{S}_{L}(t)$ - value of the additional investment resulting from the additional product produced per unit of time by an additional individual of age $a$;

$d(t, a) \tilde{S}_{E}(t)+\hat{\sigma}(t, a) d(t, a) \tilde{S}_{S}(t)=F(t) \frac{\partial(S / E)}{\partial N(t, \cdot)}(t, a)$ - change of savings due to change of the actual savings rate, resulting from one additional member of age $a$. Then $\xi^{K}(t, 0)\left(l(t, a) q(t, a) \tilde{S}_{L}(t)+d(t, a) \tilde{S}_{E}(t)+\hat{\sigma}(t, a) d(t, a) \tilde{S}_{S}(t)\right)$ is the additional value obtained by investing the additional savings resulting from an additional member of age $a$; it could be negative if $\hat{\sigma}(t, a)$ is small;

$V^{L} q(t, a) l(t, a)$ - additional welfare directly gained per unit of time from an additional worker who is employed. Notice that this gain comes from the directly consumed part of the additional production resulting from this additional worker (see the expressions for $V^{L}$ and $\left.U\right)$;

$d(t, a) V^{E}(t)$ - this term is negative: lost welfare per unit of time, caused by decrease of the per capita consumption due to an additional member of age $a$ (the other things equal);

$U_{N}(t, a)+V^{M}(t)$ - change of welfare resulting from one additional member of age $a$, due to the change of the weights in the welfare function.

Then one can interpret the adjoint equations as well.

It is interesting to compare the marginal efficiencies of the two controls involved. Since they are all expressed in different units, one first has to evaluate these efficiencies in terms of money. Therefore we define the marginal efficiencies of the controls as:

$E^{\sigma}(t)=$ additional welfare of the $a$-year old individuals, if 1 additional EURO is spent by the $a$-year old for consumption,

$E^{\nu}(t)=$ welfare value of the additional members of age $a$, resulting from 1 additional EURO spent for migration. 
Then using (6)-(7) one can express

$$
\begin{gathered}
E^{\sigma}(t)=\frac{-U_{\sigma}(t, a, \hat{\sigma}(t, a))}{\hat{y}(t, a) \hat{N}(t, a)}=\xi^{K}(t, 0), \\
E^{\nu}(t)=\frac{\int_{0}^{\omega} \xi^{N}(t, a) \nu_{0}(a) \mathrm{d} a}{m_{\nu}(t, \hat{\nu}(t, a))}=\xi^{K}(t, 0) \quad \text { if } \quad \xi^{N}(t, a)>0 .
\end{gathered}
$$

The above equalities mean that:

the marginal efficiency of the two controls is age-independent. It is the same for each of the controls, and equals the welfare value of a unit of capital. (Concerning the migration control, the above holds for ages where the individuals have positive values; otherwise the migration is zero, and the marginal efficiency of the migration control can be smaller than that of the other controls since we do not allow negative migration.)

\subsection{Numerical approach}

To solve the problem numerically we apply a gradient projection method for solving the variational inequalities (6) and (7) (subject to the primal/dual system) in the space of discretized control functions. This approach did work, despite the high dimensionality of the discretized problem (about 200000 for a discretization step of half a year). In fact, we numerically observed the 'mesh independence' phenomenon (see Alt, 1998, Dontchev et al., 2000 and Dunn, 2000), which means that the speed of convergence in the discretized (mathematical programming) problem does not depend on the size of the mesh. Thanks to this we obtained satisfactory approximations after only 10 to 40 gradient iterations.

For discretization of the differential equations along the characteristic lines we apply a second order Runge-Kutta scheme. We mention that higher order schemes would not give higher accuracy of the optimal discrete solution, since the optimal control is nondifferentiable due to the constraints (which happen to be binding in all experiments). On the other hand, the optimal controls are Lipschitz continuous and the variations of their derivatives along each characteristic line is bounded. Then in view of the results in Dontchev et al. (2000) one can expect that the optimal control of the discretized problem provides a second order approximation to the optimal control of the original problem, with respect to the uniform metric. 


\section{Optimal savings and migration}

The optimization horizon for all experiments below is $T=150$ years. However, we plot the results only for the first 100 years, since the behavior of the optimal paths is increasingly influenced by the specific choice of the planning horizon when the time approaches $T$.

For all numerical simulations we furthermore assume an upper bound on migration $\bar{\nu}(t)=80.000$, and technological progress to take place at the rate $g_{t}=0.02$. For the social welfare function we assume a discount rate of $r=0.04$ and assume utility to be concave in its argument $\alpha=0.5$. All other demographic and economic parameters and age schedules are set as outlined in Section $3 .{ }^{16}$

\subsection{Optimal Migration}

Figure 9 shows the optimal time path of total migration $\nu(t)$ setting the costs of migration equal to $m(\nu)=5 \nu+0.05 \nu^{2}$. The horizontal line at the point 20.000 represents the current annual inflow of migrants that has been assumed in the simulations of Section 3. Given a fixed age schedule of migrants as represented in Figure 5 our results suggest that it is optimal to have no migration roughly during the first 20 years of our simulations, while it is optimal to have alternating levels of migration thereafter. A comparison with Figure 7 which plots the share of working age people for our baseline simulations shows that it is optimal to increase migration during times where the share of the labor force is a minimum and to decrease migration when the share of the labor force recovers. ${ }^{17}$ Hence, it is optimal to choose migration countercyclical to the damped oscillations of the labor force participation.

Technically speaking, the optimal migration is determined by the shadow price of people $\zeta^{N}$ in comparison to the costs of migration. While the costs of migration are exogenously fixed, the shadow price of people is endogenously determined and will depend on the age structure of the prevailing economic and demographic variables. In Figure 10 we plot the shadow price of people over time and age. Obviously, the shadow price is negative for the dependent population (those of age less than 20 and

\footnotetext{
${ }^{16}$ Though the assumption of constant labor force participation rates, constant productivity levels, etc. in the future is unrealistic, it poses a benchmark case to illustrate the time path of optimal savings and optimal migration in an ageing society. More realistically, labor force participation rates and productivities will adapt in the future and thereby influence optimal time paths of savings.

${ }^{17}$ We can refer to Figure 7 in our discussion since even under optimal migration damped oscillations of the labor force will prevail.
} 


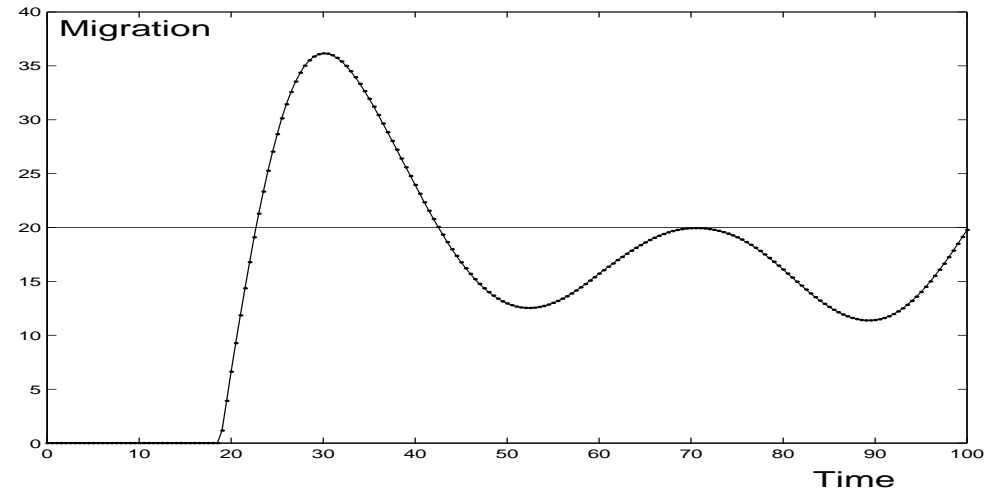

Figure 9: Optimal migration (point-wise curve) and present migration (solid line).

higher than 60 years of age) while it is positive for the working age population. Note that over time the absolute values of the shadow prices increase, i.e. the shadow price becomes more positive for the working age population while it declines further for the dependent population. Moreover we observe fluctuations of the maximum and minimum values of the shadow price which then determine the optimal time path of migration to be damped oscillations.

The choice of an optimal level of migration - compared to the baseline scenario we presented in Section 3 - results in a lower level of the total population and a lower level of the total capital stock. Figure 11 plots the optimal welfare disregarding discounting (cf. footnote 12) in comparison to the level of welfare for the baseline scenario of Section 3. Due to discounting it is optimal that utility will be increased in the initial years even if this may result in lower utilities (as compared to the baseline simulations) for later years.

\subsection{Optimal Savings}

To investigate the optimal response of savings to the aging of the population we set migration to the present annual flow of 20.000 immigrants (cf. Section 3). In addition, we assume an upper bound on age-specific savings for each year $0 \leq \sigma(t, a) \leq$ $\min \{0.9, \sigma(0, a)(1+0.05 t)\}$. In Figure 12 and Figure 13 we plot the optimal average 


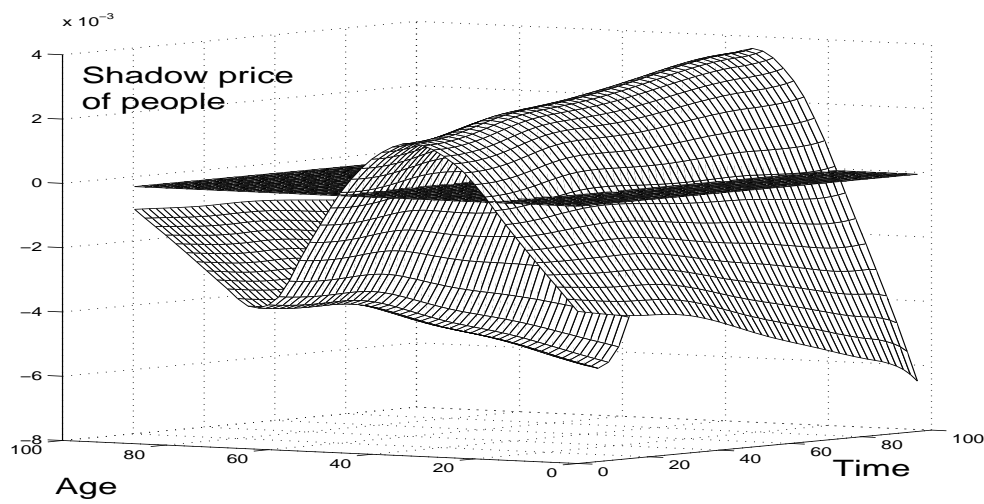

Figure 10: Shadow price of people if migration is chosen optimally. (The black manifold at the intercept zero has been added to highlight the change in the sign of the shadow price depending on the age of people.)

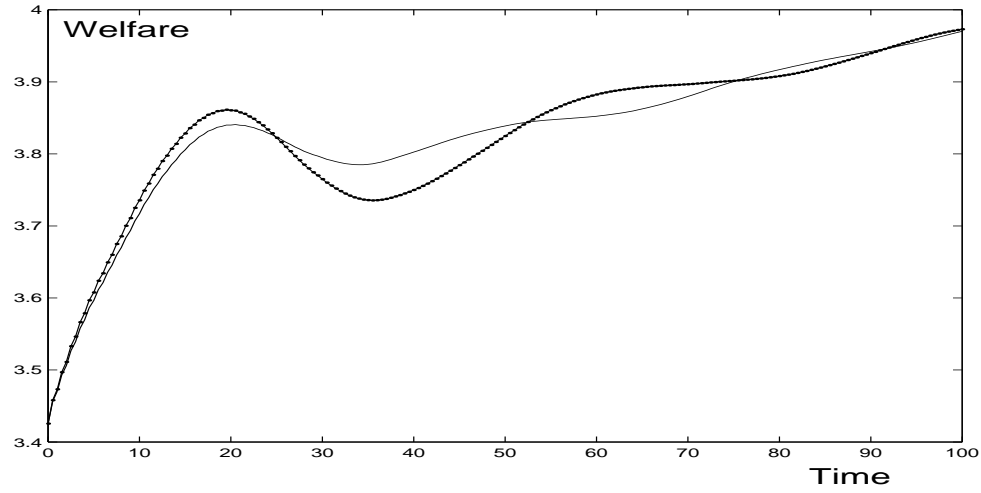

Figure 11: Aggregate welfare if migration is chosen optimally (point-wise curve) and for the present migration (solid line). 
savings rate $^{18}$ and the optimal age schedule of savings rates for selected years. According to these results it is optimal to increase savings during the first 30 periods at the maximum admissible rate and thereafter maintain savings around this obtained level (Figure 12). The aging of the population implies a shift of optimal age-specific savings rates towards older ages (Figure 13). Technically speaking, since the shadow price of new capital (i.e. capital at age zero) is high during the initial years (Figure 14), it is optimal to increase savings during the first years. In turn, the shadow price of capital is high during the first years of our simulation since the share of the labor force in the total population is high during the first 30 years of our simulations. More intuitively we may explain the optimal savings path as follows. Since savings is a means to redistribute consumption over time and since the productive capacity of the future population will be depressed by the aging of the population, it is optimal to increase savings today in order for the future population to sustain their consumption.

The optimal time path of savings results in a higher level of capital and productive capacity - compared to the baseline scenario we presented in Section 3-and consequently in a higher level of welfare for almost all subsequent years (Figure 15). Initially there will be a drop in the welfare due to the high savings. ${ }^{19}$ However this initial sacrifice in terms of obtained utility is low in terms of the reward of increased utility later on. In terms of welfare, the choice of optimal savings is more powerful as compared to the choice of an optimal migration.

\subsection{Optimal Migration and Optimal Savings}

In Figure 16 we plot the optimal level of welfare if we choose the optimal time path of migration together with the optimal rate of savings (solid line). As reference values we choose the optimal level of welfare if we only optimize w.r.t. savings (dotted line) or alternatively if we only optimize w.r.t. migration (dashed-dotted line) and the level of welfare if we assume no optimization (bold-dotted line). In addition, we plot the optimal values of migration (Figure 17), average savings (Figure 18) and the total population (Figure 19) for all four(three in case of migration) alternatives.

From these results we may conclude that savings is the more powerful control variable in terms of maximizing the social welfare. By introducing migration in addition to savings as a control variable we obtain more pronounced fluctuations in the optimal

\footnotetext{
${ }^{18}$ The averge savings rate is defined as the weighted sum of the age specific savings rates with the weights being the population shares in each age group, i.e. $\int_{0}^{\omega} \sigma(t, a) N(t, a) / M(t) d a$.

${ }^{19} \mathrm{~A}$ similar result of an immediate increase in savings that is followed by a drop in the welfare is obtained in Guest and McDonald (2002).
} 


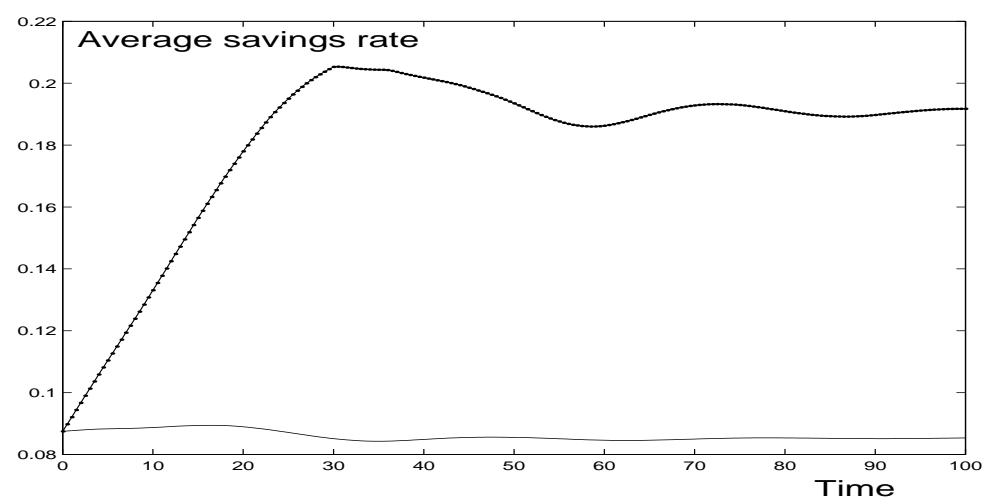

Figure 12: Optimal average savings (point-wise curve) and present average savings (solid line).

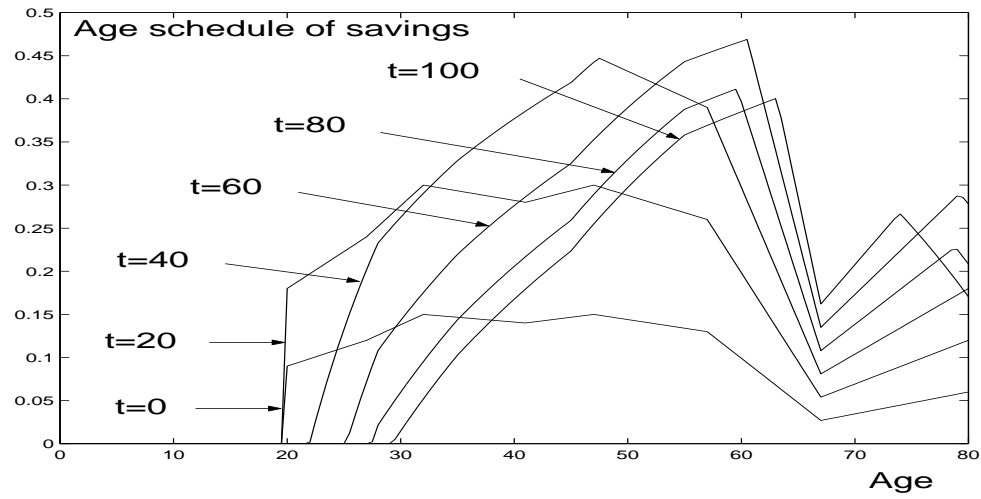

Figure 13: Optimal age specific savings for selected years. 


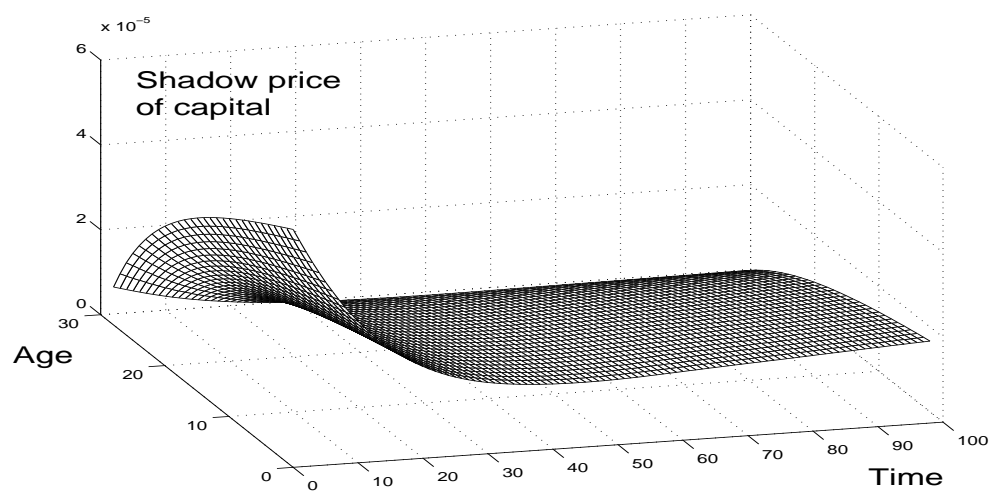

Figure 14: Shadow price of capital if savings are chosen optimally.

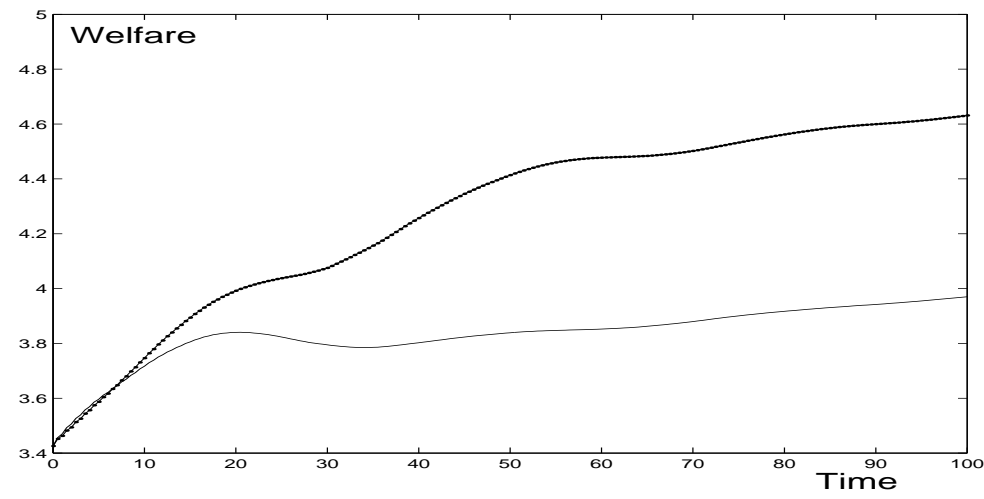

Figure 15: Aggregate welfare if savings are chosen optimally (point-wise curve) and for the present savings (solid line). 


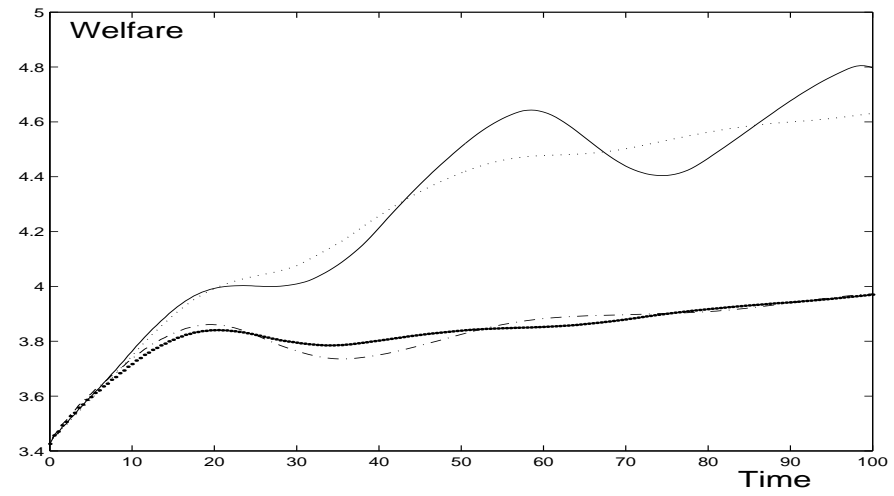

Figure 16: Aggregate welfare if savings and migration are chosen optimally (solid curve), if savings only are chosen optimally (dotted curve), if migration only is chosen optimally (dashed-dotted curve) and for the present migration and savings schedule (bold-dotted curve).

values of migration, population, savings and welfare. We may explain this result by the fact that adding savings as a control variable introduces more flexibility in terms of the age structure of the population as compared to the rigid assumption of a constant age structure of immigrants. More specifically, the choice of an optimal age structure of savings implies that the economy can better adjust to the inflow of immigrants whose age structure is assumed to be constant.

\section{Conclusions and Extensions}

The aim of the present paper is to show the applicability of a newly derived maximum principle for distributed parameter control and a corresponding numerical method to solve age structured optimal control problems in population economics. For this purpose we revisit and extend a demo-economic model analyzed by Arthur and McNicoll (1977) and confront it with the recent literature on the optimal economic and demographic response of an aging society as outlined in Cutler et al. (1990) and Guest and McDonald (2002).

A quarter of a century ago Arthur and McNicoll attempted to link two distinct traditions - intertemporal policy analysis and mathematical demography. The intention was to bring an age structure into intertemporal analysis, and a normative structure 


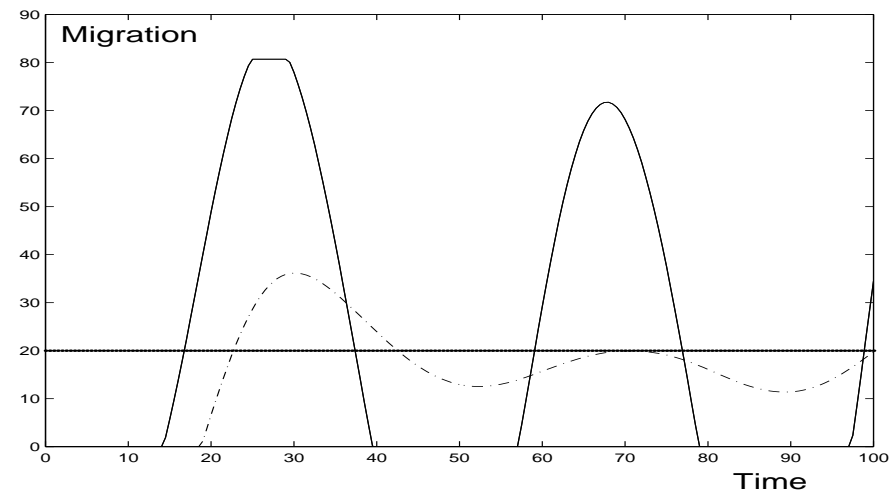

Figure 17: Optimal migration if savings and migration are chosen optimally (solid curve), if migration only is chosen optimally (dashed-dotted curve) and for the present migration and savings schedule (bold-dotted curve).

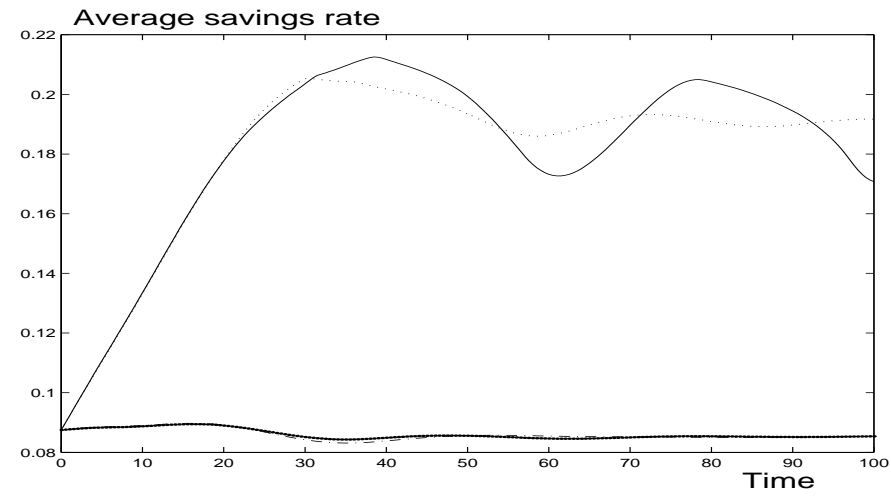

Figure 18: Optimal savings if savings and migration are chosen optimally (solid curve), if savings only are chosen optimally (dotted curve), if migration only is chosen optimally (dashed-dotted curve) and for the present migration and savings schedule (bold-dotted curve). 


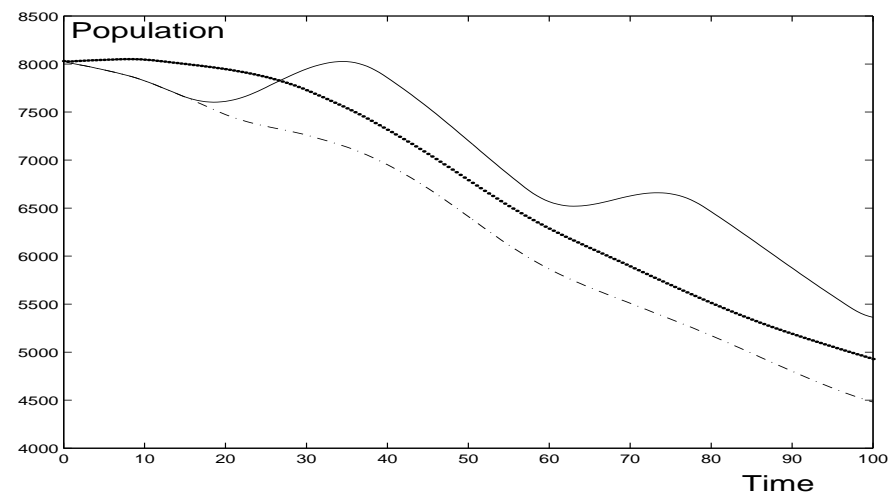

Figure 19: Optimal size of the population if savings and migration are chosen optimally (solid curve), if migration only is chosen optimally (dashed-dotted curve) and for the present migration and savings schedule (bold-dotted curve).

to population mathematics. It should be noted, however, that in economics such a 'symbiosis' has been standard since the 1960s. Overlapping-generations models deal with dynamic optimization in age-structured models. While mostly only two or three broad age groups are taken into consideration, the OLG framework is well suited also for a more detailed age structure, see e.g., Auerbach and Kotlikoff (1987) and Börsch-Supan (2001).

In the present paper we demonstrate the numerical solution for optimal age dependent controls by choosing a demographic (level of migration) and an economic (age-specific savings rate) control variable. While the age structure of migrants is held constant and we only allow the level of migration to be optimally chosen, we allow for an optimal age profile of savings rates. As the population ages our results indicate that it is optimal for the savings profile to shift towards higher ages. By admitting a more flexible age specific optimal control for the savings rates, a higher welfare can be sustained as compared to the benchmark case of no optimization or an optimization with respect to the level of migration only. Thus the age-specific savings control appears as a more powerful instrument in terms of the aggregate intertemporal welfare than the migration.

It is remarkable that optimization of the migration results in a higher consumption in the short run and in a lower consumption in some future time intervals, leading in this way to more fluctuations in the welfare. In contrast, the optimal savings result in a higher consumption for all subsequent years, except an initial drop of welfare due to high savings. This initial sacrifice allows sustaining of a higher welfare despite 
(according to the demographic data for Austria that we use) the productive capacity of the population in the years 2020-2035 being depressed due to the aging. It is also remarkable that the optimal level of migration is higher when the savings are chosen in an optimal way, than for the present savings. Thus the economy with optimal age-structure of the savings can better adjust to the inflow of immigrants.

We have deliberately refrained from using any feedback mechanisms from the demographic development on economic parameters to point out the optimal response of the migration level and the savings rates given that today's economic and demographic parameters will prevail. In further work we need to verify the sensitivity of the optimal control of migration and savings with respect to the initial age schedules of economic and demographic variables, the underlying welfare function and various alternative future scenarios of demographic (fertility, mortality and migration) and economic variables (labor force participation, age productivity, etc.). Alternatively to the scenario based approach, one may introduce the general equilibrium response of various economic variables. Furthermore, the production function should be adapted to allow for a putty clay framework in which the age structure of the population directly impacts the age structure of capital. Moreover, in further work one should allow for capital flows in addition to labour migration. As several authors have recently shown (e.g. Higgins and Williamson, 1996), the economic implications of demographic changes will depend on whether we assume that the economy is closed or open.

\section{References}

Alt, W. 1998. Discretization and mesh-independence of Newton's method for generalized equations, Lecture Notes in Pure and Appl. Math. 195, Dekker, New York, 1-30.

Arthur, W.B. and McNicoll, G. 1977. Optimal time paths with age-dependence: a theory of population policy, The Review of Economic Studies 44(1), 111-123.

Auerbach, A.J. and Kotlikoff, L.J. 1987. Dynamic Fiscal Policy, Cambridge University Press, Cambridge, MA.

Bakke, V.L., 1974. A maximum principle for an optimal control problem with integral constraints, J. Optim. Theory and Appl. 13, 32-55.

Börsch-Supan, A. 2001. Labour market effects of population aging, National Bureau of Economic Research, Working Paper No. W8640. 
Börsch-Supan, A. 2002. International Comparison of Household Savings Behaviour: The German Savings Puzzle, MEA Discussion Paper Series 06-0002, Mannheim Research Institute for the Economics of Aging, University Mannheim, Germany.

Brokate, M. 1985. Pontryagin's principle for control problems in age-dependent population dynamics, J. Math. Biology 23, 75-101.

Cutler, D.M., Poterba, J.M., Sheiner, L.M. and Summers, L.H. 1990. An Aging Society: Opportunity or Challenge, Brookings Papers on Economic Activity, Volume 1990, Issue 1, 1-56.

Dontchev, A.L., Hager, W.W. and Veliov, V.M. 2000. Uniform convergence and mesh independence of Newton's method for discretized variational problems, SIAM J. Control and Optim. 39(3), 961-980.

Dontchev, A.L., Hager, W.W. and Veliov, V.M. 2000. Second-Order Runge-Kutta Approximations in Control Constrained Optimal Control, SIAM J. Numerical Anal. 38(1), 202-226.

Dunn, J.C. 2000. On state constraint representations and mesh-dependent gradient projection convergence rates for optimal control problems, SIAM J. Control Optim. 39 (4), 1082-1111.

Feichtinger, G., Tragler, G. and Veliov, V.M. 2000. Optimality conditions for agestructured control systems. Submitted.

Feichtinger, G., Tsachev, T. and Veliov, V.M. 2002. Pontryagin's principle for age and duration structured systems: a tool for optimal prevention and treatment of HIV. Forschungsbericht 269 des Instituts für Ökonometrie, OR und Systemtheorie, TU Wien.

Guest, R.S. and McDonald, I.M. 2002. Ageing, optimal national saving and future living standards in Australia. To appear. Available under Consumption Balance at http://melbecon.unimelb.edu.au/imcdonald/balance.html.

Higgins, M. and Williamson, J.G. 1996. Asian Demography and Foreign Capital Dependence, NBER Working Paper No. 5560, Cambridge, MA.

Keyfitz, B.L. and Keyfitz, N.. 1997. The McKendrick Partial Differential Equation and Its Uses in Epidemiology and Population Study, Mathl. Comput. Modelling Vol. 26, No. 6, 1-9.

Lindh, T. 2000. Productivity slowdown due to scarcity of capital to scrap in a puttyclay model. Economics Letters 69, 225-233. 
Solow, R.M., 1959. Investment and technical progress, In K.J. Arrow, S. Karlin, and P. Suppes (Eds.), Mathematical Methods in the Social Sciences, Stanford University Press, 89-104.

Vinokurov, V.R. 1969. Optimal control of processes described by integral equations, SIAM Journal of Control 7, 324-336. 